\title{
Angiotensin-Converting Enzyme Inhibitor-Associated Angioedema Is Characterized by a Slower Degradation of des-Arginine ${ }^{9}$-Bradykinin
}

\author{
GIUSEPPE MOLINARO, MASSIMO CUGNO, MÉLISSA PEREZ, YVES LEPAGE, NICOLE GERVAIS, ANGELO AGOSTONI, \\ and ALBERT ADAM
}

Faculté de Pharmacie (G.M., M.P., N.G., A.Ad.) and Faculté des Arts et des Sciences, Département de Mathématiques et de Statistique (Y.L.), Université de Montréal, Montréal, Canada, and Department of Internal Medicine, Università di Milano, Milano, Italy (M.C., A.Ag.)

Received April 30, 2002; accepted June 4, 2002

\begin{abstract}
Angioedema $(A E)$ is a rare but potentially life-threatening side effect of therapy with inhibitors of angiotensin-converting enzyme (ACE), the main bradykinin (BK)- inactivating metallopeptidase in humans. The pathogenesis of ACE inhibitor (ACEi)associated $A E(A E+)$ is presently unknown, although there is increasing evidence of a kinin role. We analyzed the metabolism of endogenous $\mathrm{BK}\left(\mathrm{B}_{2}\right.$ receptor agonist) and its active metabolite, des- $\mathrm{Arg}^{9}-\mathrm{BK}\left(\mathrm{B}_{1}\right.$ receptor agonist), in the presence of an ACEi during in vitro contact activation of plasma from hypertensive patients $(n=39)$ who presented AE + . Kinetic parameters were compared with those measured in a control group (AE-) of hypertensive patients $(n=39)$ who never manifested any acute or chronic side effects while treated with an
\end{abstract}

ACEi. The different kinetic parameters were analyzed using a mathematical model $\left(y=\mathrm{k} \mathrm{t}^{\alpha} \mathrm{e}^{-\beta \mathrm{t}}\right)$ previously applied to a normal, healthy population. The slope of BK degradation, but not its formation from high-molecular-weight kininogen, was lower in $\mathrm{AE}+$ patients when compared with the $\mathrm{AE}$ - controls. des-Arg ${ }^{9}$-BK accumulation during the kinetic measurements was significantly higher in $A E+$ plasma. This accumulation of the $B_{1}$ agonist in $A E+$ patients paralleled its half-life of degradation. In conclusion, our results show, for the first time, that an abnormality of endogenous des-Arg ${ }^{9}$-BK degradation exists in the plasma of patients with $\mathrm{ACEi}$-associated $\mathrm{AE}$, suggesting that its pathogenetic mechanism lies in the catabolic site of kinin metabolism.
Angiotensin-converting enzyme inhibitors (ACEi) have been used successfully for 20 years in the treatment of different cardiovascular and metabolic diseases (Unger and Gohlke, 1994). Despite their clinical effectiveness, ACEi have acute side effects, the symptoms of which vary according to the clinical context (Blais et al., 2000). Although rare, these side effects are potentially life-threatening. Anaphylactoid reactions (ARs) in patients treated with ACEi have been reported during hemodialysis with a negatively charged membrane (Verresen et al., 1990), and severe hypotensive reactions have been associated with blood product transfusions or plasma and low-density lipoprotein apheresis (Owen and Brecher, 1994; Fried et al., 1996; Cyr et al., 2001a). Angioedema (AE), another side effect occurring in patients treated with ACEi for hypertension and heart failure, consists of recurrent self-limiting local swellings involving subcutaneous tissues and mucosal layers of the upper airways and bowel. Its reported frequency is apparently similar

Article, publication date, and citation information can be found at http://jpet.aspetjournals.org.

DOI: $10.1124 /$ jpet.102.038067. to that of AR and severe hypotensive reactions (Israili and Hall, 1992), although the recent OCTAVE study, involving over 25,000 hypertensive patients, has reported an overall AE incidence higher than that currently admitted. In fact, $0.68 \%$ of patients treated with enalapril exhibited an AE episode (Black, 2002). More recently, cases of AE were reported among stroke victims treated with recombinant tissue-type plasminogen activator while concomitantly medicated with an ACEi (Hill et al., 2000).

The clinical symptoms of AE have been attributed to bradykinin (BK) (Israili and Hall, 1992; Nussberger et al., 1998). $\mathrm{BK}$ is a nonapeptide, the prototype of a family of vasodilator peptides, the kinins, released from high-molecular-weight kininogen $(\mathrm{HK})$ during activation of the plasma contact system (Bhoola et al., 1992). BK exerts its pharmacological activities by binding to its $B_{2}$ receptor before being metabolized by different peptidases (Hall, 1992). The nature of these peptidases depends on the biological milieu and the pathophysiological background (Decarie et al., 1996; Erdös and Skidgel, 1997). In human plasma, we have shown that BK is

ABBREVIATIONS: ACEi, angiotensin-converting enzyme inhibitor(s); $\mathrm{AR}$, anaphylactoid reaction; $\mathrm{AE}$, angioedema; $\mathrm{AE}+, \mathrm{ACEi}-\mathrm{associated}$ angioedema; AE-, no ACEi-associated angioedema; BK, bradykinin; HK, high-molecular-weight kininogen; ACE, angiotensin-converting enzyme; APP, aminopeptidase P; AUC, area under the curve; CPN, carboxypeptidase N; des-Arg ${ }^{9}$-BK, des-arginine ${ }^{9}$-bradykinin. 
mainly metabolized by three metallopeptidases. Angiotensinconverting enzyme (ACE) and X-Pro aminopeptidase (aminopeptidase $\mathrm{P}$; APP) are, respectively, the first and second inactivating metallopeptidases in importance (Blais et al., 1999, 2000; Cyr et al., 2001b). A third enzyme, carboxypeptidase $\mathrm{N}(\mathrm{CPN})$, represents a minor metabolic pathway in the absence of ACE inhibition. It is responsible for the transformation of BK into its active metabolite, des-arginine ${ }^{9}$-bradykinin (des-Arg ${ }^{9}$-BK). This metabolite has a poor affinity for $B_{2}$ receptors but interacts with $B_{1}$ receptors, the synthesis of which is dramatically increased in experimental models of inflammation (Marceau et al., 1998). The pharmacological activities of des-Arg ${ }^{9}$-BK, similar to those of BK, are shortlived because of its breakdown by two metallopeptidases already involved in the inactivation of BK: ACE and APP. In this case, however, APP represents the main inactivating pathway in plasma (Cyr et al., 2001b).

Although an increase of plasma BK concentrations during the acute phase of $\mathrm{ACEi}$-induced $\mathrm{AE}$ was reported recently (Nussberger et al., 1998), the metabolism of endogenous kinins has yet to be documented in these patients.

The objective of the present study was to define the metabolism of endogenous BK and its active metabolite, des$\mathrm{Arg}^{9}-\mathrm{BK}$, in the plasma of hypertensive patients who presented with ACEi-associated $\mathrm{AE}(\mathrm{AE}+)$. For this purpose, we applied to these samples an analytical approach that we developed recently for a large population of normal, healthy people (Cyr et al., 2001b). The calculated kinetic parameters characterizing this metabolism have been compared with those measured for the plasma of patients who never showed any acute or chronic ACEi side effects $(\mathrm{AE}-)$.

\section{Materials and Methods}

\section{Patients}

Venous blood was obtained from 39 hypertensive patients $(20$ men, 19 women) who presented with clinically documented $\mathrm{AE}+$. These patients were from the University of Milan (Milan, Italy), the Academische Ziekenhuis (Leuven, Belgium), and Hôpital du SacréCoeur (Montréal, QC, Canada). All the patients were white; their age ranged from 40 to 78 years; and they received enalapril, quinapril, ramipril, fosinopril, or captopril to treat systemic hypertension. $\mathrm{AE}$ occurred between 1 day and 8 years after the initiation of therapy and affected the tongue, lips, face, eyelids, and buccal mucosa. At the time of $\mathrm{AE}$, patients were treated with histamine receptor $\mathrm{H}_{1}$ and $\mathrm{H}_{2}$ blockers, epinephrine, and steroids. At the time of blood sampling (between 1 and 70 months after AE episodes), ACEi therapy had been discontinued except in 5 patients who presented recurrent (two to six) episodes before ACEi therapy was discontinued.

Control plasma was obtained from 39 white hypertensive patients (with similar mean age and sex proportion) who never developed any acute (AE, AR, severe hypotensive reactions) or chronic (cough, diarrhea or gastrointestinal disturbance, peripheral edema) side effects while treated with an ACEi. AE - patients were from the University of Milan, the Academische Ziekenhuis, and the Centre Hospitalier de l'Université de Montréal (Montréal, QC, Canada). At the time of blood sampling, these patients were still treated with an ACEi. All patients from the different centers were selected according to the same questionnaire.

\section{Blood Samples}

This study was reviewed and approved by the ethics committee for research on human subjects from the teaching hospitals of the Uni- versities of Montréal, Milan, and Leuven, and informed consent was obtained from all patients.

Twenty milliliters of blood were sampled by venipuncture from the forearm into tubes containing $0.1 \mathrm{~mol} / \mathrm{l}$ sodium citrate as anticoagulant ( 1 volume of sodium citrate to 9 volumes of blood). After centrifugation $\left(22^{\circ} \mathrm{C}, 15 \mathrm{~min}, 2500 \mathrm{~g}\right)$, the plasma samples were decanted and stored at $-80^{\circ} \mathrm{C}$ until biochemical investigation.

\section{Drugs, Peptides, and Reagents.}

BK and des-Arg ${ }^{9}$-BK were acquired from Peninsula Laboratories (Belmont, CA). The ACEi enalaprilat was obtained from Merck Frosst Canada (Kirkland, QC, Canada). High-pressure liquid chromatography-grade ethanol was obtained from American Chemicals (Montréal, QC, Canada).

\section{Metabolism of Endogenous BK and des-Arg ${ }^{9}$-BK}

Contact System Activation. Plasma was activated as described earlier for normal healthy people (Cyr et al., 2001b). Briefly, $1 \mathrm{ml}$ of plasma was preincubated with enalaprilat for $20 \mathrm{~min}$ at $37^{\circ} \mathrm{C}$ in polypropylene tubes at a concentration $(130 \mathrm{nM})$ that totally inhibits ACE activity. The contact system was then activated by incubation of the plasma with glass beads $\left(37^{\circ} \mathrm{C}\right.$, with agitation). The reaction was stopped after various incubation periods $(0-60 \mathrm{~min}$ for $\mathrm{BK}$, and 0-120 min for des-Arg ${ }^{9}$-BK) by adding cold anhydrous ethanol at a final concentration of $80 \%(\mathrm{v} / \mathrm{v})$. The samples were then incubated at $4^{\circ} \mathrm{C}$ for $1 \mathrm{~h}$ and centrifuged $\left(4^{\circ} \mathrm{C}, 15 \mathrm{~min}, 3000 \mathrm{~g}\right)$ for the complete precipitation of kinin precursors. The supernatant was decanted and evaporated to dryness in a SpeedVac concentrator (Thermo Savant, Holbrook, NY). The residues were stored at $-80^{\circ} \mathrm{C}$ until quantification of the immunoreactive peptides $\mathrm{BK}$ and des-Arg ${ }^{9}$-BK.

\section{Quantification of BK and des-Arg ${ }^{9}$-BK}

The residues of evaporated ethanolic extracts were resuspended in $50 \mathrm{mM}$ Tris/HCl buffer, $\mathrm{pH}$ 7.4, containing $100 \mathrm{mM} \mathrm{NaCl}$ and $0.05 \%$ Tween 20. After resuspension, residual BK and formed des-Arg ${ }^{9}$-BK were quantified by two specific competitive enzyme immunoassays, as described previously (Decarie et al., 1994; Raymond et al., 1995). These methods have been validated and their analytical performances reported (Blais et al., 2000).

\section{Mathematical Treatment}

The following mathematical model, $y=k t^{\alpha} \mathrm{e}^{-\beta t}, t>0$, was fitted to the concentrations of endogenous BK and des-Arg ${ }^{9}-\mathrm{BK}$ measured at different times $(t)$ for each $\mathrm{AE}+$ and $\mathrm{AE}$ - subject. This three-parameter ( $k, \alpha$, and $\beta ; k>0, \alpha$ and $\beta \geq 0$ ) model corresponds to a form similar to gamma distribution (Rice, 1995) and has been described and validated earlier (Cyr et al., 2001b). The $\alpha$ and $\beta$ parameters are, respectively, related to the shape of the first and the second part of the curve corresponding to the formation and the degradation of each peptide. These $\alpha$ and $\beta$ parameters allow the calculation of other kinetic parameters: time of the maximum, the value of $t$ for which the maximum of the curve was obtained $t=\alpha / \beta$; maximum, the value of the maximum of the curve, which corresponds to the value of the curve for $t=\alpha / \beta$; AUC, the area under the curve, which is mathematically given by $k \Gamma(\alpha$ $+1) / \beta^{\alpha+1}$, where $\Gamma(\alpha+1)$ is the gamma function; half-life of formation $\left(t_{\mathrm{f}}\right)$, the value $t_{\mathrm{f}}$ in the interval 0 to $\alpha / \beta$ for which $t^{\alpha} e^{-\beta t}=(0.5)(\alpha / \beta)^{\alpha} e^{-\alpha}$; half-life of degradation $\left(t_{\mathrm{d}}\right)$, the value $t_{\mathrm{d}}$ in the interval $\alpha / \beta$ to $\infty$ for which $t^{\alpha} \mathrm{e}^{-\beta t}=(0.5)(\alpha / \beta)^{\alpha} e^{-\alpha}$; slope of the half-life of formation, the value of the slope of the curve at half-life formation $=k e^{-\beta t_{\mathrm{f}}} t_{\mathrm{f}}^{\alpha-1}\left(\alpha-\beta t_{\mathrm{f}}\right)$; and slope of the half-life of degradation, the value of the slope of the curve at half-life degradation: $k e^{-\beta t_{\mathrm{d}}} t_{\mathrm{d}}{ }^{\alpha-1}\left(\alpha-\beta t_{\mathrm{d}}\right)$.

\section{Statistical Analysis}

The means of the parameters of the two groups ( $\mathrm{AE}+$ and $\mathrm{AE}-$ ) were compared, using a $t$ test with the Satterwaite-Welch approach and taking into account the possible heterogeneity of variances 
(Neter et al., 1996). $p$ values less than 0.05 were considered statistically significant.

\section{Results}

Plasma Metabolism of Endogenous BK and desArg-BK from $\mathbf{A E}+$ and $\mathbf{A E}-$ Patients. Figure 1 illustrates the comparative profiles of the patient means for the synthesis and degradation of BK and its active metabolite, des-Arg ${ }^{9}-\mathrm{BK}$, measured during the activation of $\mathrm{AE}+$ and $\mathrm{AE}$ - plasma in the presence of an $\mathrm{ACEi}$, with the mean reference population profile published earlier (Cyr et al., 2001b). The mathematical model parallels the actual measured concentrations and illustrates a clear difference in the kinetic profiles of the $\mathrm{B}_{1}$ receptor agonist, des-Arg ${ }^{9}$-BK, between $\mathrm{AE}+$ and $\mathrm{AE}$ - patients.

For $\mathrm{BK}$, no difference between $\mathrm{AE}+$ and $\mathrm{AE}-$ plasma could be calculated for the different kinetic parameters $\left(\alpha, t_{\mathrm{f}}\right.$, slope) characterizing the ascending part of the curve. The latter represents the kinetics of generation of this peptide from HK (Ta- ble 1). The $\beta$ parameter and its slope, which reflects the catabolism of the $\mathrm{B}_{2}$ agonist by APP and kininase I in the presence of ACE inhibition, were lower $(p=0.022$ and $p=0.016$, respectively) in $\mathrm{AE}+$ samples compared with the $\mathrm{AE}$ - control group. However, no difference could be detected for the maximal concentration and total amount of BK formed, as reflected by a similar AUC during the 60-min observation period.

The main metabolic differences between $\mathrm{AE}+$ and $\mathrm{AE}-$ patients were calculated for des-Arg ${ }^{9}$-BK. These results (Table 1) are illustrated in Figs. 1 and 2. The AUC, reflecting des-Arg ${ }^{9}$-BK accumulation during the 120-min incubation period, was significantly higher in the $\mathrm{AE}+$ group ( $p=$ 0.005). Similarly, a higher maximal concentration of the peptide $(p=0.001)$, which was also delayed in time $(p=0.030)$, was observed for these patients. These anomalies are related to an important difference affecting the degradation of the $B_{1}$ receptor agonist, as reflected in a lower $\beta$ value $(p<0.001)$ and a higher half-life of degradation, $t_{\mathrm{d}}(p=0.001)$, in the $\mathrm{AE}+$ group. Although the $\alpha$ value was lower for $\mathrm{AE}+$ sam-
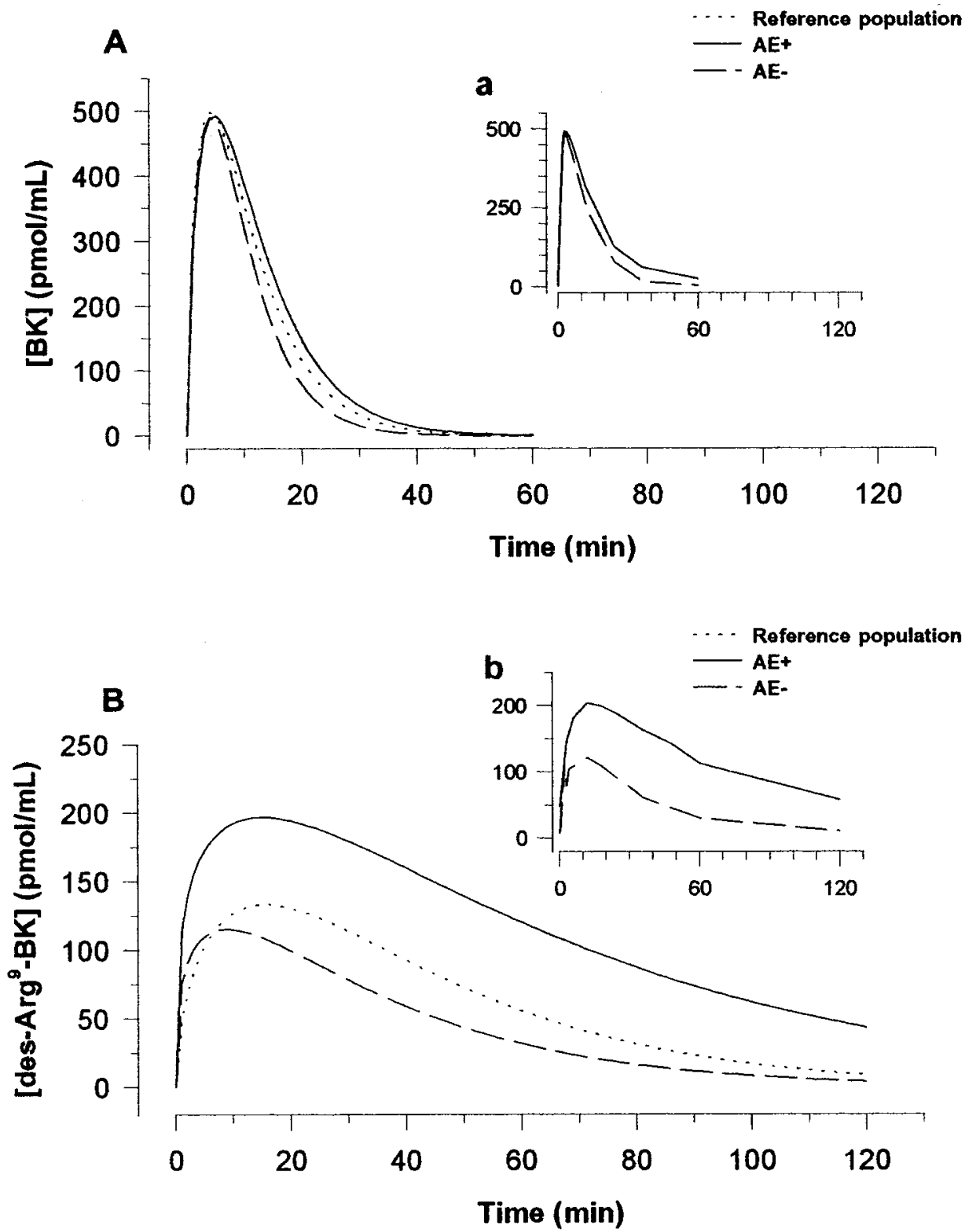

Fig. 1. Kinetic gamma model-fitted profiles of formation and degradation of $\mathrm{BK}(\mathrm{A})$ and des-Arg ${ }^{9}-\mathrm{BK}(\mathrm{B})$ for mean $\mathrm{AE}+$ (solid line) and $\mathrm{AE}-$ (dashed line) patients after activation of the contact system, in the presence of enalaprilat, with glass beads. Dotted lines are values for reference population. Superscript graphs (a and b) are actual measured value profiles. 
TABLE 1

Parameters characterizing the gamma model fitted to endogenous measurements of kinins

Data represent means \pm S.D.

\begin{tabular}{|c|c|c|c|c|}
\hline \multirow{2}{*}{ Parameter } & \multicolumn{2}{|c|}{ BK $(n=39)$} & \multicolumn{2}{|c|}{ 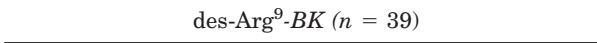 } \\
\hline & $\mathrm{AE}-$ & $\mathrm{AE}+$ & $\mathrm{AE}-$ & $\mathrm{AE}+$ \\
\hline \multirow[t]{2}{*}{$\alpha$} & $0.94 \pm 0.53$ & $0.75 \pm 0.31$ & $0.85 \pm 0.35$ & $0.62 \pm 0.33$ \\
\hline & \multicolumn{2}{|c|}{$p=0.055$} & \multicolumn{2}{|c|}{$p=0.004$} \\
\hline \multirow{2}{*}{ Slope of the $t_{1 / 2}$ of formation } & $22,992 \pm 7,572$ & $27,105 \pm 31,838$ & $2.65 \mathrm{E} 10 \pm 1.65 \mathrm{E} 11$ & $5.48 \mathrm{E} 7 \pm 3.17 \mathrm{E} 8$ \\
\hline & \multicolumn{2}{|c|}{$p=0.435$} & \multicolumn{2}{|c|}{$p=0.325$} \\
\hline$t_{1 / 2}$ of formation (min) & $0.86 \pm 0.29$ & $0.82 \pm 0.49$ & $2.32 \pm 1.26$ & $2.61 \pm 2.47$ \\
\hline Maximum (nM) & \multicolumn{2}{|c|}{$p=0.809$} & \multicolumn{2}{|c|}{$p=0.001$} \\
\hline \multirow[t]{2}{*}{ Time of maximum (min) } & $4.2 \pm 0.8$ & $6.1 \pm 8.1$ & $12.1 \pm 6.6$ & $16.9 \pm 11.3$ \\
\hline & \multicolumn{2}{|c|}{$p=0.152$} & \multicolumn{2}{|c|}{$p=0.030$} \\
\hline \multirow[t]{2}{*}{$\beta$} & $0.24 \pm 0.17$ & $0.16 \pm 0.08$ & $0.08 \pm 0.04$ & $0.05 \pm 0.03$ \\
\hline & \multicolumn{2}{|c|}{$p=0.022$} & \multicolumn{2}{|c|}{$p<0.001$} \\
\hline$t_{1 / 2}$ of degradation (min) & \multicolumn{2}{|c|}{$p=0.191$} & \multicolumn{2}{|c|}{$p=0.001$} \\
\hline \multirow[t]{2}{*}{$\mathrm{AUC}(\mathrm{pmol} / \mathrm{ml} \cdot 60 \mathrm{~min}$ or $120 \mathrm{~min})$} & $6,305 \pm 2,247$ & $16,175 \pm 48,333$ & $5,660 \pm 5,214$ & $1.64 \mathrm{E} 6 \pm 2.26 \mathrm{E} 6$ \\
\hline & \multicolumn{2}{|c|}{$p=0.207$} & \multicolumn{2}{|c|}{$p=0.005$} \\
\hline
\end{tabular}

ples, no significant differences could be measured for the $t_{1 / 2}$ of formation and its slope.

Comparison of des-Arg'-BK Metabolism in AE+ Patients, AE- Patients, and a Reference Population. The kinetic parameters of des-Arg ${ }^{9}$-BK metabolism were different for $\mathrm{AE}+$ and $\mathrm{AE}$ - plasma and have been compared with the mean values calculated earlier for the reference population. As illustrated in Fig. 2, significantly higher values in $\mathrm{AE}+$ samples were calculated for the AUC $(p=0.030)$, for the maximal concentration of peptide generated $(p=0.008)$, and the $t_{\mathrm{d}}$ half-life of degradation $(p=0.036)$. The $\beta$ value was significantly lower in $\mathrm{AE}+$ samples $(p=0.004)$. For the same parameters in AE - patients, significantly lower values were calculated for the AUC $(p=0.012)$ and the half-life of degradation $t_{\mathrm{d}}(p=0.032)$. The $\beta$ value was significantly higher $(p=0.039)$. No significant difference with the reference population could be calculated for the various kinetic parameters characterizing des-Arg ${ }^{9}-\mathrm{BK}$ formation in the $\mathrm{AE}+$ and $\mathrm{AE}-$ groups.

Influence of the Time of AE Occurrence and the Time of Blood Sampling. The influence of the time interval between the start of medication and the AE episode on the kinetic parameters characterizing des-Arg ${ }^{9}$-BK metabolism in the $\mathrm{AE}+$ group was considered at three levels: 1 month or less, 1 year or less, and more than 1 year. One-way analysis of variance did not allow the measurement of significant differences in $\beta$ values among these three time intervals. Similarly, we could not measure a significant effect of the time between $\mathrm{AE}$ and blood sampling (1 year or less, 2 years or less, or more than 2 years).

\section{Discussion}

In this article, we provide evidence, for the first time, of an anomaly affecting the degradation of endogenous kinins, mainly of des-Arg ${ }^{9}$-BK, in the plasma of patients who presented ACEi-associated AE. These results must be discussed in light of our previous observations on the same patients, showing a significant decrease of APP activity, but no difference of CPN activity in AE+ patients when compared with the $\mathrm{AE}-$ control group and the reference population (Adam et al., 2002).

The experimental approach used in this paper has been developed recently in our laboratory and validated by application to a large number of normal, healthy people (Cyr et al., 2001b). It uses glass beads, a well known activator of the plasma contact system (Kaplan et al., 1998). The kinetic studies in AE+ and $\mathrm{AE}$ - groups of plasma were performed in the presence of an ACEi to mimic what would happen in vivo in the plasma of patients treated with such a drug. ACEi also increases the transformation of BK into des-Arg ${ }^{9}$-BK, which otherwise represents a minor metabolic pathway in humans (Decarie et al., 1996; Cyr et al., 2001b). We assessed the pharmacokinetic characteristics of this activation. The release and the degradation of endogenous BK and des-Arg ${ }^{9}$-BK formed during the activation process have been measured, using highly sensitive and specific immunoassays developed in our laboratory (Decarie et al., 1994; Raymond et al., 1995). These assays employ highly specific antibodies to the carboxy-terminal end of both peptides, which is responsible for $\mathrm{B}_{2}(\mathrm{BK})$ and $\mathrm{B}_{1}$ (des-Arg $\left.{ }^{9}-\mathrm{BK}\right)$ pharmacological activity, respectively.

Under our experimental conditions, we did not find evidence of any abnormality in the formation of BK from HK. In fact, the $\alpha, t_{f}$, and slope of the $t_{f}$ parameters, the values of which are related to formation of the peptide, were similar in both $\mathrm{AE}+$ and AE- plasma. These observations argue against a quantitative or qualitative defect in one of the constituents of the contact system (Factor XII, prokallikrein, or HK). Also unlikely is a defect of antiproteases responsible for the control of this system, even though quantitative or qualitative defects of $\mathrm{C} 1$ esterase inhibitor have been associated with hereditary angioneurotic edema (Agostoni and Cicardi, 1992).

The degradation of BK in the presence of an ACEi, how- 

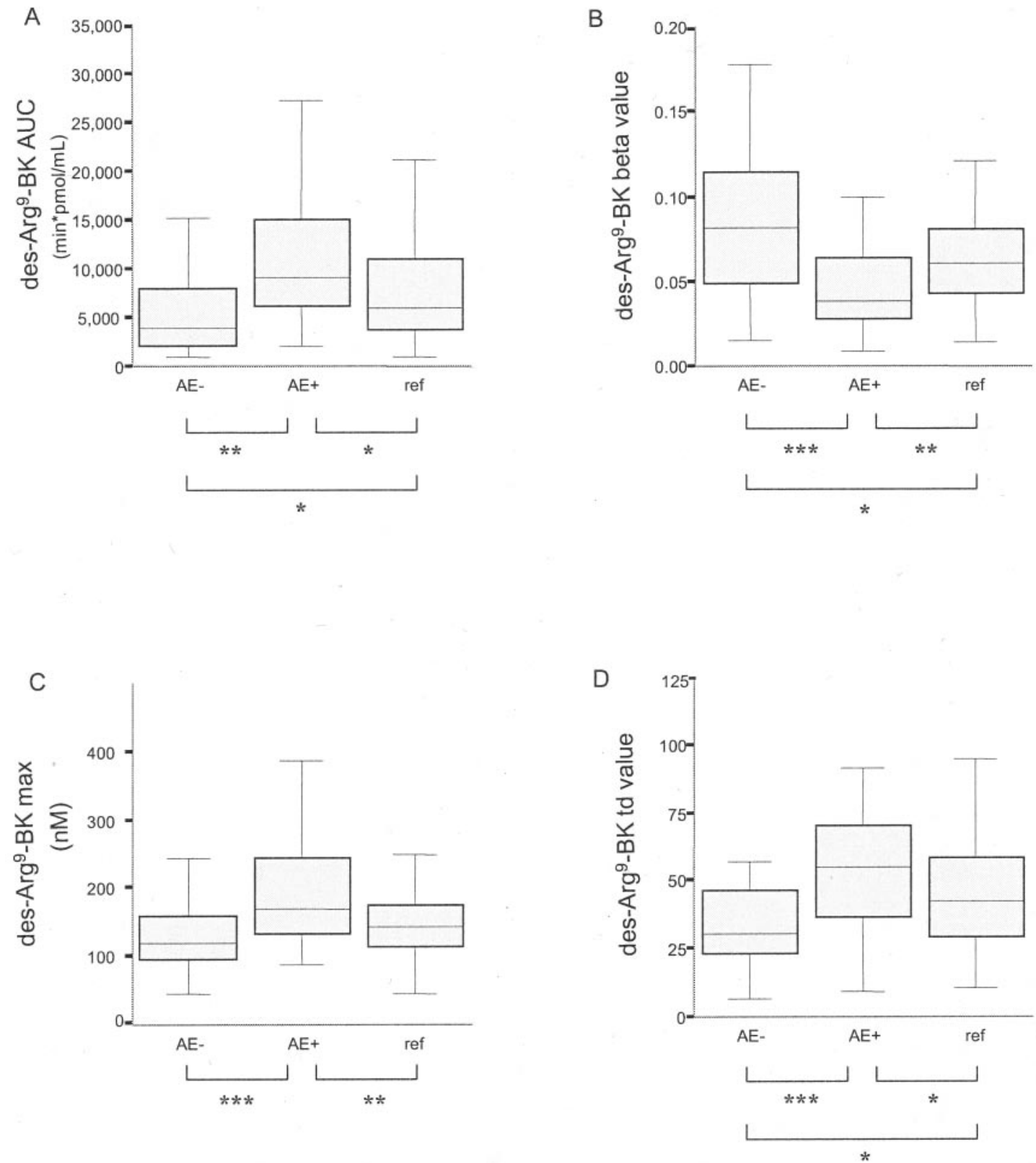

Fig. 2. Panels representing des-Arg ${ }^{9}-\mathrm{BK}$ area under the curve (panel A), des-Arg ${ }^{9}-\mathrm{BK} \beta$ values (panel B), des-Arg ${ }^{9}-\mathrm{BK}$ maximal concentration (panel $\mathrm{C}$ ), and des-Arg. ${ }^{9}-\mathrm{BK} t_{\mathrm{d}}$ value (panel $\left.\mathrm{D}\right)$. Values measured in $\mathrm{AE}+$ and $\mathrm{AE}-$ patients $(n=39)$, both compared with the reference population value $(n$ $=109$ ), are shown. Box plots display summary statistics for the distribution. The lower boundary of the box is the 25th percentile and the upper boundary is the 75th percentile. The line in the box represents the median. The largest and smallest values that are not outliers are also shown. Lines are drawn from the ends of the box to these values. $\star, p<0.05 ; \star \star, p<0.01 ; \star \star \star, p \leq 0.001$

ever, is statistically slower in $\mathrm{AE}+$ than in $\mathrm{AE}-$ control patients. Despite significant $p$ values, these differences are not sufficient to lead to an increased concentration of BK during the activation period. Our observations may be explained by the fact that even in the presence of a decreased activity of APP and ACE inhibition, BK is still transformed into des-Arg9-BK by CPN.

The accumulation of des-Arg ${ }^{9}-\mathrm{BK}$, as assessed by the AUC, is significantly higher in $\mathrm{AE}+$ when compared with $\mathrm{AE}-$ plasmas. As CPN activities are similar in both groups of samples, this increase of $\mathrm{B}_{1}$ agonist concentration is a consequence of a decrease of its metabolism by APP, a pivotal degrading enzyme in the presence of an ACEi (Adam et al., 2002). Contrary to our observations with BK, the differences affecting inactivation of the $B_{1}$ agonist are strongly significant, as reflected by the $p$ values near and below 0.001 for $\beta$ and the half-life of degradation $\left(t_{\mathrm{d}}\right)$. These strong differences explain the much more pronounced accumulation of des$\mathrm{Arg}^{9}$-BK during the activation of $\mathrm{AE}+$ plasma.

Our in vitro observations are physiologically relevant. In fact, we have previously evidenced in vivo that an accumulation of immunoreactive des-Arg ${ }^{9}$-BK parallels a proinflammatory effect mediated by the $B_{1}$ receptors (Blais et al., 1997). Although the pharmacological role of $B_{1}$ agonist and its receptors has been characterized in different experimental models, such a role in human pathology has been poorly defined (Marceau et al., 1998). We have, however, recently described an anomaly in the degradation of exogenous des-Arg ${ }^{9}$-BK added to the plasma 
of patients who presented an AR while treated with an ACEi and dialyzed with a negatively charged membrane (Blais et al., 1999). It is well known that these dialyzed patients are chronically inflamed and exhibit high concentrations of blood proinflammatory cytokines, well known to induce the $\mathrm{B}_{1}$ receptor in animals (Pertosa et al., 2000). Although both $B_{1}$ and $B_{2}$ kinin receptor subtypes exhibit some structural homology, similar signaling pathways and similar pharmacological consequences, functional responses show two main differences (Faussner et al., 1999). On the one hand, $B_{1}$ receptors are inducible, whereas $\mathrm{B}_{2}$ receptors are constitutively present. On the other hand, some evidence now exists for an agonist-induced temporary desensitization of $\mathrm{B}_{2}$ receptors involving receptor phosphorylation and endocytosis (Blaukat et al., 1996; Faussner et al., 1999). Furthermore, some recent evidence suggests that chronic $\mathrm{ACE}$ inhibition itself induces functional vascular and renal $\mathrm{B}_{1}$ receptor expression, possibly involving homologous up-regulation (Marin-Castano et al., 2002). Another group has also reported that enalaprilat and other ACEi could directly activate human $B_{1}$ receptors, even in the absence of an exogenous $B_{1}$ receptor agonist (Ignjatovic et al., 2002). In this case, however, the presence of endogenous kinin was not documented.

As plasma BK has been previously shown to be increased during the acute episode of AE (Nussberger et al., 1998), this peptide could initiate the inflammatory process via the $\mathrm{B}_{2}$ receptor, thereafter relayed by des-Arg ${ }^{9}-\mathrm{BK}$ and stimulating its $\mathrm{B}_{1}$ receptor. These findings do not mean that des-Arg ${ }^{9}-\mathrm{BK}$ is necessarily the only mediator of $\mathrm{AE}$. In fact, some pharmacological evidence suggests that kinins could lead to the local release of neurokinins, particularly the sensory neuropeptide substance P (Ferreira et al., 2000). Interestingly, in this regard, a decrease in dipeptidyl peptidase IV activity, a substance Pdegrading enzyme, was also reported in a limited number of hypertensive patients during ACEi-associated AE (Lefebvre et al., 2002). Thus, a multifactorial nature of ACEi-associated AE is expected and could explain its rarity. This side effect results from the gathering of at least three different factors: pharmacological (ACEi treatment), metabolic, and triggering factors. Our data clearly show an anomaly in the degradation of endogenous des-Arg' ${ }^{-B K}$ in the plasma of patients with ACEi-associated $\mathrm{AE}$, suggesting that its pathogenetic mechanism lies in the catabolic site of kinin metabolism. However, the triggering factors responsible for in vivo kinin release remain to be defined. In this regard, recently reported $\mathrm{AE}$ associated with recombinant tissue-type plasminogen activator used in stroke (Francis et al., 1991; Hill et al., 2000), with its capacity to activate the kinin-forming cascade in vitro (Molinaro et al., 2002), could bring new insights.

\section{Acknowledgments}

We are grateful to Dr. F. Bertrand (Hôpital du Sacré-Coeur, Montréal, Canada), Dr. P. Larochelle (Centre hospitalier de l'Université de Montréal, Montréal, Canada), and Dr. T. Messiaen (Academische Ziekenhuis, Leuven, Belgium) for providing some AE+ and/or AEsamples. We also thank Miguel Chagnon for assistance in statistical analysis and graph design.

\section{References}

Adam A, Cugno M, Molinaro G, Perez M, Lepage Y, and Agostoni A (2002) Aminopeptidase $\mathrm{P}$ in individuals with a history of angio-edema on ACE inhibitors. Lancet, 359:2088-2089.

Agostoni A and Cicardi M (1992) Hereditary and acquired C1-inhibitor deficiency: biological and clinical characteristics in 235 patients. Medicine (Baltim) 71:206-215.
Bhoola KD, Figueroa CD, and Worthy K (1992) Bioregulation of kinins: kallikreins, kininogens and kininases. Pharmacol Rev 44:1-80.

Black H (2002) Omapatrilat cardiovascular treatment assessment versus enalapril (OCTAVE): results of a landmark clinical trial, in An Advanced Approach to the Management of Cardiovascular Disease: The Role of Vasopeptidase Inhibition, 2002 March 20, Atlanta, GA.

Blais C Jr, Couture R, Drapeau G, Colman RW, and Adam A (1997) Involvement of endogenous kinins in the pathogenesis of peptidoglycan-induced arthritis in the Lewis rat. Arthritis Rheum 40:1327-1333.

Blais C Jr, Marc-Aurele J, Simmons WH, Loute G, Thibault P, Skidgel RA, and Adam A (1999) Des-Arg'-bradykinin metabolism in patients who presented hypersensitivity reactions during hemodialysis: role of serum ACE and aminopeptidase P. Peptides 20:421-430.

Blais C Jr, Marceau F, Rouleau JL, and Adam A (2000) The kallikrein-kininogenkinin system: lessons from the quantification of endogenous kinins. Peptides 21:1903-1940.

Blaukat A, Alla SA, Lohse MJ, and Muller-Esterl W (1996) Ligand-induced phosphorylation/dephosphorylation of the endogenous bradykinin $\mathrm{B}_{2}$ receptor from human fibroblasts. J Biol Chem 271:32366-32374.

Cyr M, Eastlund T, Blais C Jr, Rouleau JL, and Adam A (2001a) Bradykinin metabolism and hypotensive transfusion reactions. Transfusion 41:136-150.

Cyr M, Lepage Y, Blais C Jr, Gervais N, Cugno M, Rouleau JL, and Adam A (2001b) Bradykinin and des-Arg(9)-bradykinin metabolic pathways and kinetics of activation of human plasma. Am J Physiol 281:H275-H283.

Decarie A, Drapeau G, Closset J, Couture R, and Adam A (1994) Development of digoxigenin-labeled peptide: application to chemiluminoenzyme immunoassay of bradykinin in inflamed tissues. Peptides 15:511-518.

Decarie A, Raymond P, Gervais N, Couture R, and Adam A (1996) Serum interspecies differences in metabolic pathways of bradykinin and [des-Arg9]BK: influence of enalaprilat. Am J Physiol 271:H1340-H1347.

Erdös E and Skidgel R (1997) Metabolism of bradykinin by peptidases in health and disease, in The Kinin System (Farmer S ed) pp 111-141, Academic Press, San Diego.

Faussner A, Bathon JM, and Proud D (1999) Comparison of the responses of B1 and B2 kinin receptors to agonist stimulation. Immunopharmacology 45:13-20.

Ferreira PK, Campos MM, and Calixto JB (2000) The role of sensorial neuropeptides in the edematogenic responses mediated by $\mathrm{B}(1)$ agonist des-Arg(9)-BK in rats pre-treated with LPS. Regul Pept 89:29-35.

Francis CW, Brenner B, Leddy JP, and Marder VJ (1991) Angioedema during therapy with recombinant tissue plasminogen activator. $\mathrm{Br}$ J Haematol 77:562-563.

Fried MR, Eastlund T, Christie B, Mullin GT, and Key NS (1996) Hypotensive reactions to white cell-reduced plasma in a patient undergoing angiotensinconverting enzyme inhibitor therapy. Transfusion 36:900-903.

Hall JM (1992) Bradykinin receptors: pharmacological properties and biological roles. Pharmacol Ther 56:131-190.

Hill MD, Barber PA, Takahashi J, Demchuk AM, Feasby TE, and Buchan AM (2000) Anaphylactoid reactions and angioedema during alteplase treatment of acute ischemic stroke. Can Med Assoc J 162:1281-1284.

Ignjatovic T, Tan F, Brovkovych V, Skidgel RA, and Erdos EG (2002) Novel mode of action of angiotensin I-converting enzyme inhibitors: direct activation of bradykinin $\mathrm{B}_{1}$ receptor. J Biol Chem 277:16847-16852.

Israili ZH and Hall WD (1992) Cough and angioneurotic edema associated with angiotensin-converting enzyme inhibitor therapy. A review of the literature and pathophysiology. Ann Intern Med 117:234-242.

Kaplan AP, Joseph K, Shibayama Y, Nakazawa Y, Ghebrehiwet B, Reddigari S, and Silverberg M (1998) Bradykinin formation. Plasma and tissue pathways and cellular interactions. Clin Rev Allergy Immunol 16:403-429.

Lefebvre J, Murphey LJ, Hartert TV, Jiao Shan R, Simmons WH, and Brown NJ (2002) Dipeptidyl peptidase IV activity in patients with ACEi-associated angioedema. Hypertension 39:460-464.

Marceau F, Hess JF, and Bachvarov DR (1998) The $\mathrm{B}_{1}$ receptors for kinins. Pharmacol Rev 50:357-386.

Marin-Castano ME, Schanstra JP, Neau E, Praddaude F, Pecher C, Ader JL, Girolami JP, and Bascands JL (2002) Induction of functional bradykinin b(1)-receptors in normotensive rats and mice under chronic angiotensin-converting enzyme inhibitor treatment. Circulation 105:627-632.

Molinaro G, Gervais N, and Adam A (2002) Biochemical basis of angioedema associated with recombinant tissue-plasminogen activator treatment: an in vitro experimental approach. Stroke 33:1712-1716

Neter J, Wasserman W, and Kutner M (1996) Applied Linear Statistical Models. Irwing, Chicago.

Nussberger J, Cugno M, Amstutz C, Cicardi M, Pellacani A, and Agostoni A (1998) Plasma bradykinin in angio-oedema. Lancet 351:1693-1697.

Owen HG and Brecher ME (1994) Atypical reactions associated with use of angiotensin-converting enzyme inhibitors and apheresis. Transfusion 34:891-894.

Pertosa G, Grandaliano G, Gesualdo L, and Schena FP (2000) Clinical relevance of cytokine production in hemodialysis. Kidney Int 58 (Suppl 76):S104-S111.

Raymond P, Drapeau G, Raut R, Audet R, Marceau F, Ong H, and Adam A (1995) Quantification of des-Arg9-bradykinin using a chemiluminescence enzyme immunoassay: application to its kinetic profile during plasma activation. J Immunol Methods 180:247-257. Rice J (1995) Mathematical Statistics and Data Analysis. Duxbury Press, Belmont, CA Unger T and Gohlke P (1994) Converting enzyme inhibitors in cardiovascular therapy: current status and future potential. Cardiovasc Res 28:146-158.

Verresen L, Waer M, Vanrenterghem Y, and Michielsen P (1990) Angiotensinconverting-enzyme inhibitors and anaphylactoid reactions to high-flux membrane dialysis. Lancet 336:1360-1362.

Address correspondence to: Dr. Albert Adam, Faculté de pharmacie, Université de Montréal, 2900 Boulevard Édouard-Montpetit, C.P. 6128, succursale Centre-ville, Montréal (Québec) Canada H3C 3J7. E-mail: albert.adam@umontreal.ca 